\title{
Effects of Sevoflurane and Propofol Anesthesia on Cerebral Oxygenation in Patients Undergoing Carotid Endarterectomy
}

\author{
Zeynep CURA ${ }^{1}$, Bahar OC ${ }^{1}$, Oguzhan ARUN¹, Mehmet OC², Ipek DUMAN ${ }^{3}$, Ates DUMAN ${ }^{1}$ \\ ${ }^{1}$ Selcuk University, School of Medicine, Department of Anesthesiology and Intensive Care, Konya, Turkey \\ 2Selcuk University, School of Medicine, Department of Cardiovascular Surgery, Konya, Turkey \\ ${ }^{3}$ Necmettin Erbakan University, Meram School of Medicine, Department of Medical Pharmacology, Konya, Turkey
}

Corresponding author: Ipek DUMAN ipekduman@yahoo.com

\section{ABSTRACT}

AIM: To compare the effects of sevoflurane and propofol anesthesia on perioperative cerebral oxygenation in patients undergoing carotid endarterectomy (CEA) under general anesthesia by using near-infrared spectroscopy (NIRS) monitoring.

MATERIAL and METHODS: Institutional approval was obtained, and the perioperative data of 33 patients undergoing CEA were retrospectively evaluated. The study groups were organized according to the anesthesia drugs used for maintenance: sevoflurane $(n=17)$ and propofol $(n=16)$. The regional cerebral oxygen saturation $\left(\mathrm{rScO}_{2}\right)$ of the ipsilateral and contralateral hemispheres was monitored continuously using a NIRS instrument and analyzed at specific time points starting from induction to the $12^{\text {th }}$ hour postoperation. The data were analyzed using the appropriate tests, and a $p$ value of $<0.05$ was considered significant.

RESULTS: Compared with those of groups with non-clamped hemispheres, the $\mathrm{rScO}_{2}$ values of the sevoflurane and propofol groups decreased significantly during clamping $(p<0.05)$ and increased to above-preoperative values after declamping $(p<0.05)$. When the sevoflurane and propofol groups were compared, a significant decrease in $\mathrm{rScO}_{2}$ was noted during extubation in the sevoflurane group $(p<0.05)$. In the propofol group, female patients had significantly lower $\mathrm{rScO}_{2}$ values compared with male patients during clamping of the carotid artery $(p<0.05)$. None of the observed decreases was greater than $20 \%$, which is considered an indication for shunting.

CONCLUSION: Our NIRS monitoring results indicate that sevoflurane or propofol anesthesia does not generally cause significant differences in cerebral oxygenation during and after cross-clamping in patients undergoing CEA. The finding of sex-related differences in cerebral oxygenation in patients receiving propofol and decreased oxygenation during extubation in patients receiving sevoflurane warrants further studies.

KEYWORDS: Carotid endarterectomy, Cerebral oxygenation, Near-infrared spectroscopy, Propofol, Sevoflurane

\section{INTRODUCTION}

S troke is the fifth leading cause of registered resident deaths in the United States and the second leading cause of death in patients with cardiovascular diseases worldwide $(8,2)$. Atherosclerotic carotid stenosis is the main cause of ischemic stroke. Carotid endarterectomy (CEA) in combination with medical therapy is superior to medical therapy alone in individuals with high-grade ( $>70 \%$ angiographic stenosis) carotid stenosis $(19,38)$. The advantages and disadvantages of local and general anesthesia during CEA are well recognized. Data from existing randomized controlled trials (RCTs) show no difference in the neurological outcomes of local and general anesthesia (11). General anesthesia allows optimal patient positioning, excellent control of ventilation and oxygenation, and improved comfort for the patient and surgeon. However, intraoperative neurological monitoring with general anesthesia
Zeynep CURA (D): 0000-0003-2808-371X

Bahar OC OC: 0000-0002-2253-5191

Oguzhan ARUN (I) : 0000-0001-6101-1481
Mehmet OC (10: :0000-0002-7832-3067

Ipek DUMAN (D) : 0000-0002-0079-6374

Ates DUMAN (1) : 0000-0003-0394-2485 
is more complicated and less sensitive than that with local anesthesia $(22,16)$.

CEA requires clamping of the ipsilateral carotid artery. Most patients can tolerate clamping because they have sufficient intra-cerebral collateral blood flow. Electroencephalography, somatosensory- and motor-evoked potentials, carotid stump pressure, transcranial Doppler, and cerebral oximetry are commonly used to detect cerebral hypoperfusion and ischemia during clamping under general anesthesia. None of these modalities is superior to the other (22).

Cerebral oximetry is based on near-infrared spectroscopy (NIRS) and measures the hemoglobin oxygen saturation of the mixed arterial, capillary, and venous blood $\left(\mathrm{rScO}_{2}\right)(25)$. Real-time critical reductions in cerebral circulation can be detected by NIRS monitoring. Significant reductions in $\mathrm{rScO}_{2}$ during carotid artery clamping are observed when occlusion leads to a decrease in ipsilateral or contralateral cerebral perfusion (34,31). Earlier studies considered NIRS to have high sensitivity and specificity for detecting cerebral ischemia in patients receiving CEA under general anesthesia (37).

Total intravenous anesthesia (TIVA) with propofol and inhalational anesthesia with sevoflurane are two of the most frequent anesthesia-maintenance techniques. Previous reports concerning the beneficial effects of propofol and sevoflurane for cerebral protection describe conflicting results $(10,23,29)$. On the one hand, volatile anesthetic agents, including sevoflurane, provide neuroprotection during carotid clamping by decreasing the cerebral metabolic rate $\left(\mathrm{CMRO}_{2}\right)$ and causing intrinsic dose-dependent cerebral vasodilation $(9,26)$. On the other hand, propofol has been shown to have neuroprotective effects, which are attributed mainly to its free radical scavenging and anti-inflammatory properties (26). Information regarding the impact of the anesthesia technique on the neurological outcomes of CEA patients is limited. Thus, the present retrospective study compares the effects of sevoflurane and propofol anesthesia on regional cerebral oxygenation in patients undergoing carotid endarterectomy with clamping of the carotid artery by using NIRS monitoring.

\section{MATERIAL and METHODS}

Approval to conduct this study was obtained from the Institutional Ethics Committee. The perioperative anesthesia and ICU data of patients between the ages of 50 and 80 years, American Society of Anesthesiologists classes I-III, and undergoing CEA were retrospectively evaluated. Patients with a history of lung disease and heart failure, those with renal impairment (creatinine $>2 \mathrm{mg} / \mathrm{dl}$ ) or emergency surgery, patients with a history of cancer, and patients confirmed to be hemodynamically unstable during anesthesia were excluded from this analysis. The study groups were organized according to the anesthesia drugs used for maintenance: sevoflurane $(n=17)$ and propofol (TIVA; $n=16)$.

Anesthesia was provided using standard protocols without premedication. Monitoring consisted of ECG, intermittent noninvasive blood pressure, invasive arterial blood pressure, body temperature, pulse oximetry, and capnography. After 3 min of preoxygenation, induction of anesthesia with propofol (2-2.5 $\mathrm{mg} / \mathrm{kg})$, rocuronium $(0.6 \mathrm{mg} / \mathrm{kg})$, and fentanyl $(2 \mathrm{mg} / \mathrm{kg}$ ) was performed in both groups; tracheal intubation followed shortly after. In the sevoflurane group, anesthesia was maintained with 1-1.3 MAC of sevoflurane in $100 \%-50 \%$ oxygen; in the propofol group, anesthesia was maintained with 6-10 mg/ $\mathrm{kg} / \mathrm{h}$ propofol and $0.5-1.5 \mu \mathrm{g} / \mathrm{kg} / \mathrm{min}$ remifentanil. The drugs were adjusted manually according to the patients' mean arterial pressure and heart rate. Mechanical ventilation was initiated after intubation with $50 \%$ oxygen, a tidal volume of 8-10 ml/kg, a positive end-expiratory pressure of $5 \mathrm{cmH}_{2} \mathrm{O}$, and a respiratory rate to maintain an end-tidal carbon dioxide $\left(\mathrm{EtCO}_{2}\right)$ of $30-35 \mathrm{mmHg}$ were obtained. $\mathrm{FiO}_{2}$ was increased to 1.0 , and $120 \mathrm{IU} / \mathrm{kg}$ heparin was administered prior to clamping. At the end of the procedure, the patients were transferred to the ICU and received sedation and mechanical ventilation. Patients were extubated in the ICU when they woke up and reacted to the endotracheal tube.

\section{Monitoring \\ Cerebral Oximetry}

The $\mathrm{rScO}_{2}$ of the ipsilateral and contralateral hemispheres was monitored continuously using a NIRS instrument (INVOS 5100 C; Somanetics, Troy, MI, USA) during the perioperative period, and the data of specific timepoints were transferred to a computer in Excel format (INVOS Monitoring System Analysis Program), selectively registered, and analyzed. These timepoints are as follows: awake before induction; during induction; 5 minutes after intubation; 5 minutes after $\mathrm{fiO}_{2}$ was reduced to $50 \%$; before carotid clamping; 3, 5, 15, and 30 minutes after clamping; after the release of the clamp, during transfer, during intensive care; pre and post extubation, and the $12^{\text {th }}$ hour postoperation. A decrease in the ipsilateral hemisphere $\mathrm{rScO}_{2}$ of greater than $20 \%$ is considered an indication for shunt placement (31).

Invasive arterial blood pressure results were recorded continuously. Mean arterial pressure was recorded and analyzed at the same time points considered in the NIRS recordings.

The data were analyzed using the Kolmogorov-Smirnov, Mann-Whitney $\mathrm{U}$, and $t$-tests as appropriate. The $\mathrm{rScO}_{2}$ data are presented as mean $\pm \mathrm{SE}$, and a $\mathrm{p}$ value of $<0.05$ was considered significant.

\section{RESULTS}

The records of 39 patients were reviewed. Six patients (Figure 1) were eventually excluded from the analysis because of cardiovascular instability $(n=4)$ and renal impairment $(n=2)$.

The demographic characteristics and preoperative health status of all eligible 33 patients in the sevoflurane and propofol groups are described in Table I. Among the patients, 20 were male $(60.6 \%), 13$ were female (39.4\%), and the mean age was $69.1 \pm 9.3$ years. Nineteen patients had right carotid artery stenosis, while 14 patients had left carotid artery stenosis. The most frequent comorbidities reported were hypertension $(51.2 \%)$ and diabetes (23\%). A total of 14 and 5 patients 


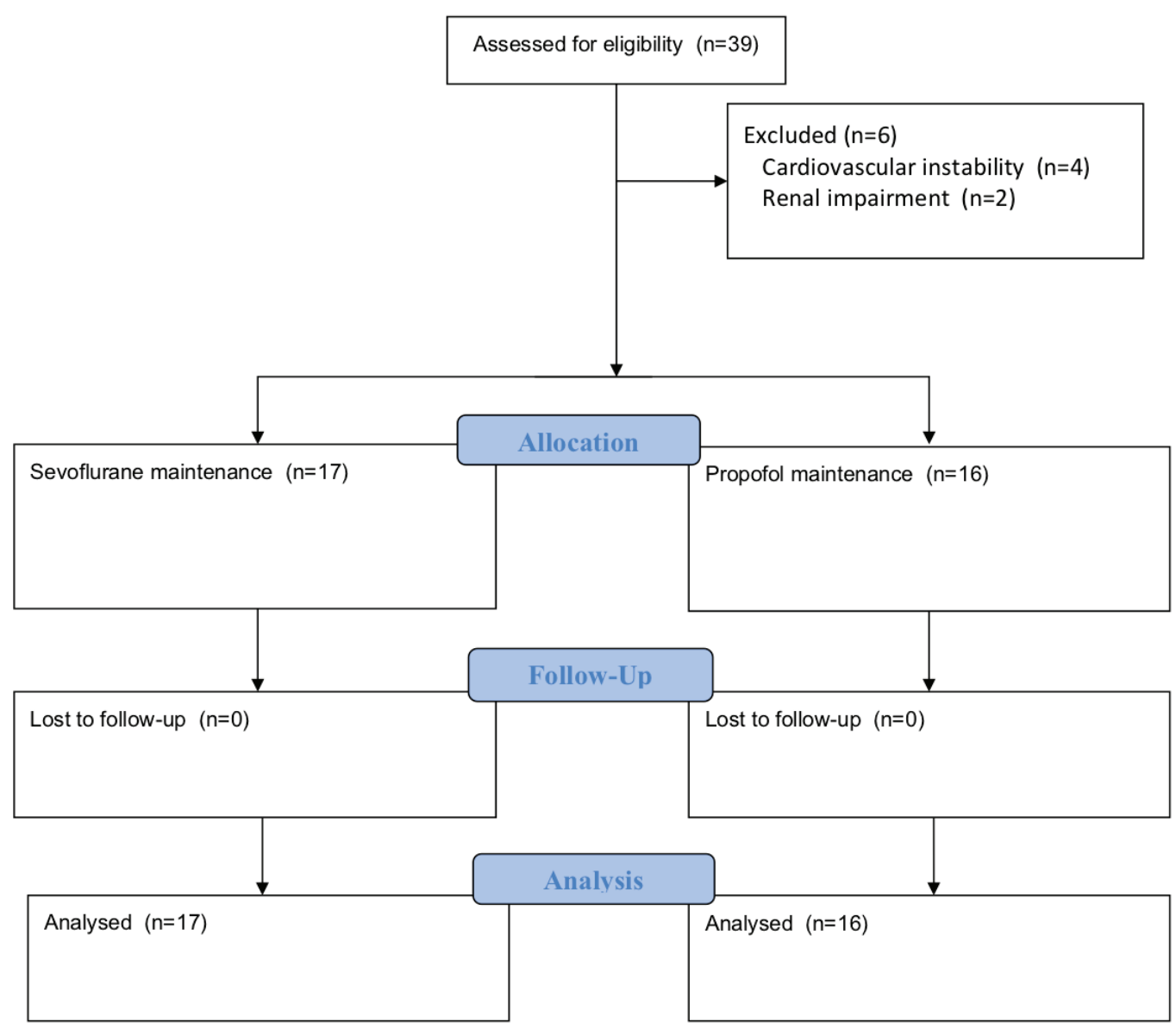

Figure 1: Patient recruitment flowchart.

Table I: Demographic Characteristics and Preoperative Health Status of the Patients. Data are Presented as Number of Patients (n) or mean $\pm \mathrm{SD}, \mathrm{p}<0.05=$ Significant

\begin{tabular}{|c|c|c|c|}
\hline & $\begin{array}{c}\text { Sevoflurane } \\
n=17\end{array}$ & $\begin{array}{l}\text { TIVA } \\
\mathrm{n}=16\end{array}$ & $\mathbf{P}$ \\
\hline Sex (M/F) & $10 / 7$ & $10 / 6$ & $>0.05$ \\
\hline Age (years) & $71.1 \pm 9.0$ & $66.1 \pm 9.9$ & $>0.05$ \\
\hline ASA score & 2.8 & 2.8 & $>0.05$ \\
\hline Side of surgery R/L (n) & $12 / 5$ & $9 / 7$ & $>0.05$ \\
\hline Diabetes (n) & 2 & 7 & $>0.05$ \\
\hline Hypertension (n) & 10 & 10 & $>0.05$ \\
\hline COPD (n) & 2 & 2 & $>0.05$ \\
\hline Preoperative TIA-Stroke (n) & 8 & 6 & $>0.05$ \\
\hline Postoperative TIA-Stroke (n) & 4 & 1 & $>0.05$ \\
\hline Duration of surgery (min) & 107.4 & 109.4 & $>0.05$ \\
\hline Duration of cross-clamp (min) & 37.0 & 37.0 & $>0.05$ \\
\hline Duration of anesthesia (min) & 135.0 & 138.4 & $>0.05$ \\
\hline Extubation time (min) & 306 & 294 & $>0.05$ \\
\hline
\end{tabular}


respectively suffered from transient ischemic attack/stroke before and after surgery. No significant differences in the demographic characteristics and preoperative health status of the patients were observed between the two groups.

The MAP values between male and female patients and patients receiving sevoflurane or propofol for maintenance were similar $(p>0.05)$.

\section{Cerebral Oximetry}

Compared with the contralateral (non-clamped) hemisphere, $\mathrm{rScO}_{2}$ values decreased significantly in the ipsilateral (clamped) hemisphere in the sevoflurane and propofol groups during clamping of the carotid artery $(p<0.05)$ and increased to above-preoperative values after declamping $(p<0.05)$. Although a significant decrease in $\mathrm{rScO}_{2}$ was observed during extubation in the sevoflurane group, the $\mathrm{rScO}_{2}$ values of the ipsilateral hemisphere were generally similar between the sevoflurane and propofol groups in all measurements $(p<0.05$; Figure 2).

When the patients were grouped as male and female, significant differences in $\mathrm{rScO}_{2}$ values in the ipsilateral hemisphere during cross-clamping were observed between male and female patients in the propofol group. Female patients showed significantly lower $\mathrm{rScO}_{2}$ values compared with male patients during clamping of the carotid artery $(p<0.05$; Figure 3$)$.

No patient required intraoperative shunting.

\section{DISCUSSION}

The human brain consumes large amounts of oxygen and is susceptible to ischemia/hypoxia (6). Ischemia of the brain leads to the release of excitatory amino acids, resulting in receptor activation, followed by metabolic dysfunction and oxidative stress (39). Thus, global or focal brain ischemia may lead to a large variety of neurological injuries, manifesting in several forms ranging from a short-term decline in cognitive function to persistent physical dysfunction or even death. CAE is effective in preventing stroke in patients with symptomatic carotid stenosis but is not without its complications. Carotid clamping, for example may lead to ischemia on the brain's ipsilateral side if the contralateral flow is unable to compensate for the lack of blood flow $(31,34)$.

Debris from atherosclerotic plaques can result in a distal stroke. The incidence of perioperative stroke during CEA is $2.3 \%$ (3). Detecting perioperative ischemia promptly and protecting the brain during the ischemic insult are of great importance. Cerebral oximetry is non-invasive, continuous, and easy to interpret. NIRS presents some limitations. For instance, NIRS only reflects oxygen saturation in the brain's focal areas, and large inter-individual differences due to extracranial blood flow, including the scalp, arterial oxygen saturation, and hemoglobin concentration, may be obtained. Although these limitations hinder the assessment of $\mathrm{rScO}_{2}$ data as an absolute value, continuous monitoring of $\mathrm{rScO}_{2}$ changes during CEA surgery can detect ischemia. No consensus on an optimal cut-off value for $\mathrm{rScO}_{2}$ has yet been achieved, but cerebral perfusion reduction is well correlated with postoperative neurologic deficits $(7,31,32,34,35)$. Earlier studies considered a relative decrease of $11.7 \%-25 \%$ in $\mathrm{rScO}_{2}$ value as a significant reduction in cerebral oxygenation $(22,37)$. Yu et al. determined the cut-off value of change in $\mathrm{rScO}_{2}$ for predicting the need for intervention during $\mathrm{CAE}$ to be $16 \%$. The sensitivity and specificity of $\mathrm{rScO}_{2}$ were $70.8 \%$ and $91.1 \%$, respectively (37). In practice, a decrease in $\mathrm{rScO}_{2}$ of greater than $20 \%$ is considered a clinically critical decrease and indication for shunt placement (31).

The present work presents a real-life retrospective observational study. RCTs offer advantages in evidence generation as controlled standard methods such as

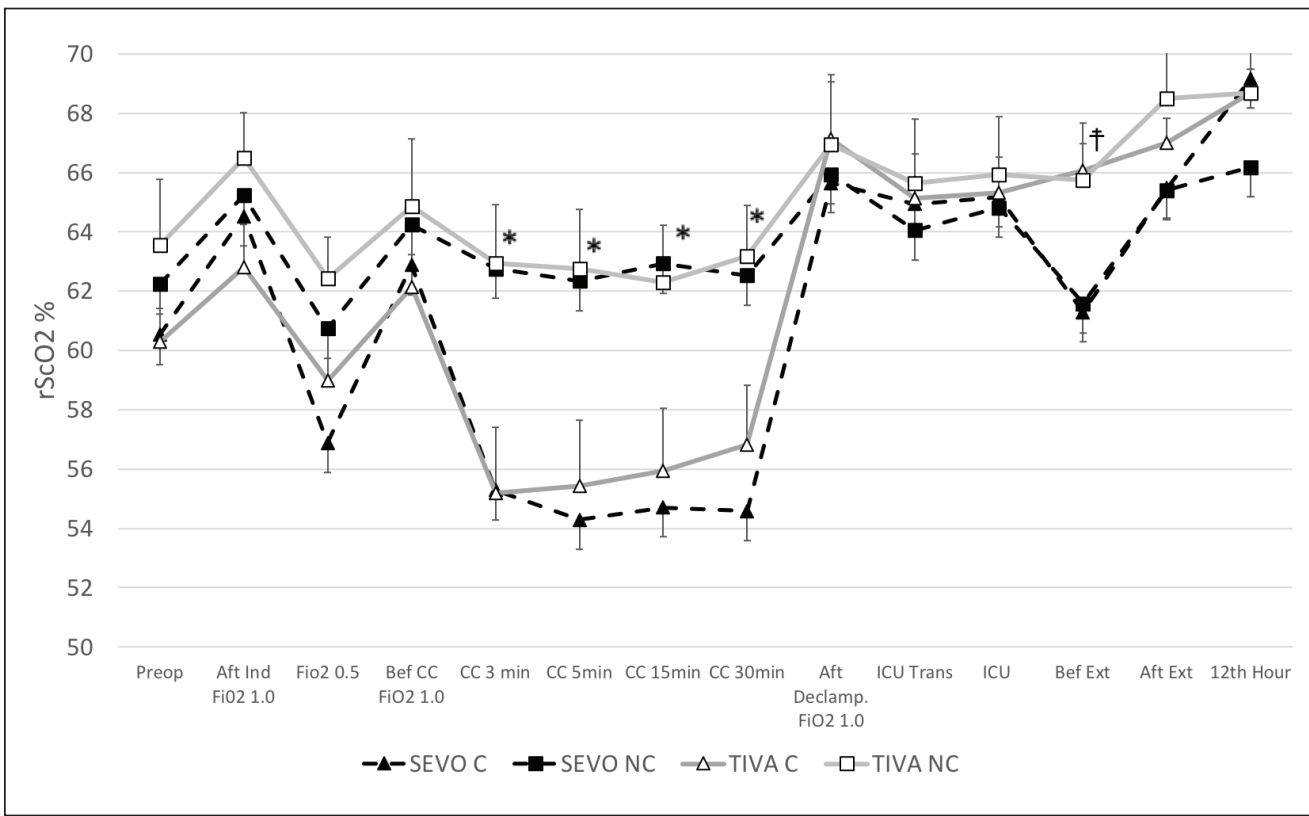

Figure 2: Comparison of the $\mathrm{rScO}_{2}$ values of the clamped (ipsilateral) and non-clamped (contralateral) hemispheres of patients receiving sevoflurane (SEVO; broken black line) or propofol (TIVA; grey line) during and after carotid endarterectomy. Triangle: clamped (C), square: nonclamped (NC). Data are presented as mean \pm SEM, ${ }^{*} \mathrm{p}<0.05$ compared with clamped hemispheres, $p<0.05$ compared with the SEVO group. 


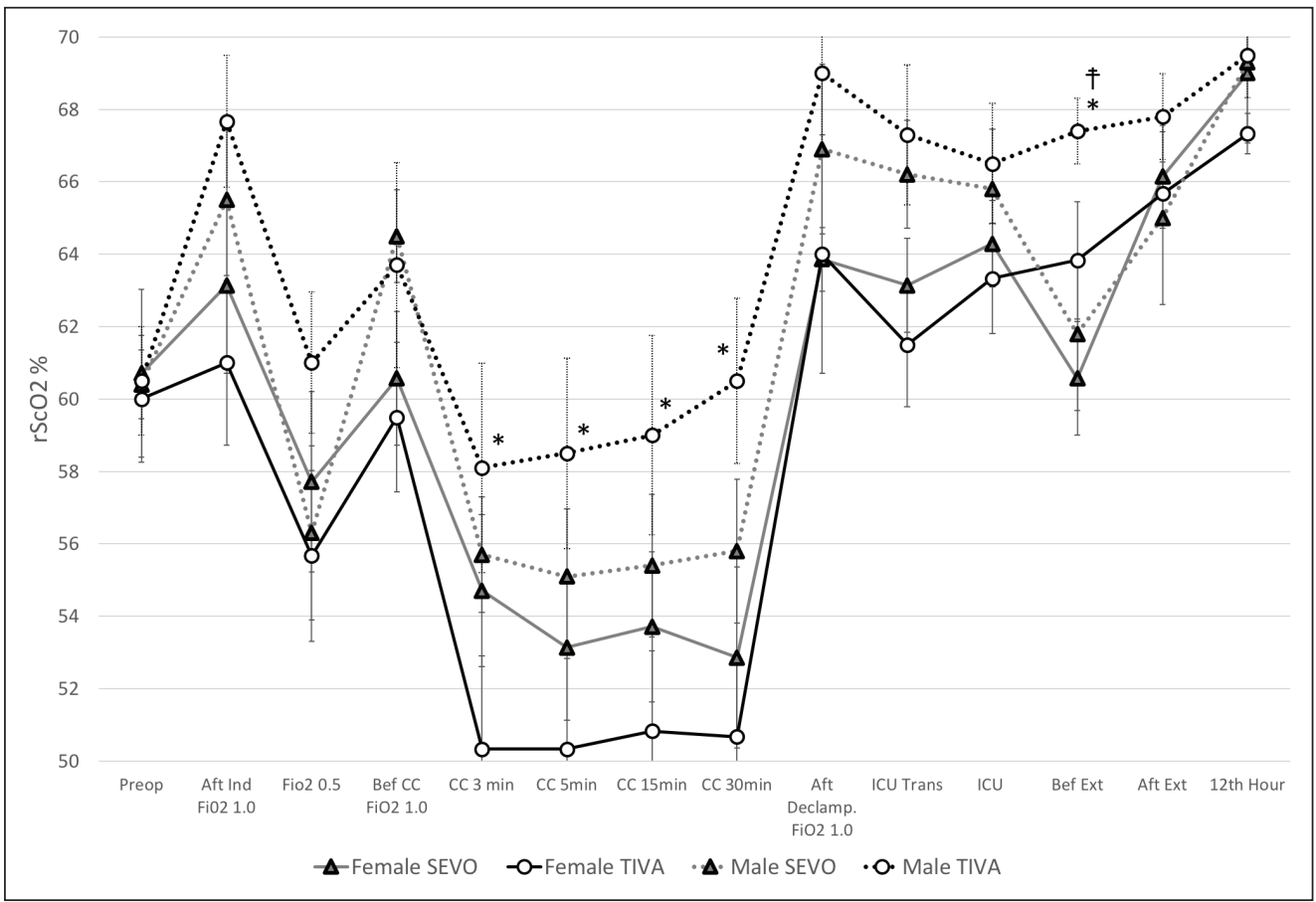

Figure 3: Comparison of the $\mathrm{rScO}_{2}$ values of the clamped (ipsilateral) carotid artery of male (dotted line) and female (straight line) patients during and after carotid endarterectomy. Data are presented as mean \pm SE. Square: sevoflurane group (SEVO), circle: propofol (TIVA) group. * $\mathrm{p}<0.05$ compared with female patients, $\mathrm{p}<0.05$ compared with the SEVO group. randomization and blinding to reduce bias, and demonstrate efficacy against active and placebo controls. However, RCTs may not accurately reveal real-world data because the clinical circumstances under which patients are treated are often different from those in controlled conditions; thus, real-life observational studies are necessary to provide additional information on the safety and effectiveness of a medication or technique $(1,17)$. Previous RCTs comparing the effects of propofol and sevoflurane anesthesia among non-vascular surgery patients suggested that sevoflurane is better than propofol for maintaining cerebral oxygen balance $(12,20)$. In contrast to these studies, Park et al. showed that propofolremifentanil anesthesia is comparable with sevofluraneremifentanil anesthesia in preserving cerebral oxygen balance in patients undergoing carotid endarterectomy with carotid cross-clamping, as assessed by NIRS (30). Our results support the findings of Park et al. and revealed a statistically significant difference in cerebral oximetry values between male and female patients receiving propofol anesthesia during cross-clamping of the carotid artery.

As expected, $\mathrm{rScO}_{2}$ levels in the present study increased during induction and endotracheal intubation with $100 \%$ oxygen, returned to normal with $50 \%$ oxygen while preparing for carotid artery clamping, and increased once more when oxygen was increased to $100 \%$ before the cross-clamp. The mean $\mathrm{rScO}_{2}$ was similar between the ipsilateral and contralateral hemispheres from induction until carotid artery clamping. Similar to earlier results, the decrease in mean $\mathrm{rScO}_{2}$ noted in the present work was significantly different between the two hemispheres $(18,30)$. $\mathrm{rScO}_{2}$ values were significantly lower in the sevoflurane group than in the propofol group before extubation in the ICU and in female patients than in male patients in the propofol group during cross-clamping.
While our results are consistent with the expected reduction in unilateral blood flow during and after cross-clamping in both groups, no patient experienced a decrease of over $20 \%$ in $\mathrm{rScO}_{2}$, indicating sufficient collateral flow.

Our results show significantly lower oxygenation in the clamped hemisphere during the ischemic period in female patients receiving propofol anesthesia compared with that of males in the same group. Previous experimental studies suggested a difference in microcirculation oxygenation between male and female patients during ischemia. Kao and Sun used NIRS to detect gender differences in microcirculation in healthy adults and found a difference in oxygenation status between males and females during microcirculation intervention by far-infrared illumination (FIR) (15). Moreover, the authors' results showed a significant increase in hemoglobin oxygen saturation in male subjects but steady levels in female subjects. The authors thus argued that, besides hormone-dependent differences in vascular function between the sexes, the ratio of skeletal muscle and subcutaneous fat thickness varies according to sex. Propofol is known to decrease cerebral blood flow and cerebral perfusion pressure. Kim et al. showed significantly lower $\mathrm{rScO}_{2}$ values in women receiving propofol than sevoflurane during gynecological laparoscopic surgery. The authors thus warned of a possible cerebral desaturation in women under propofol anesthesia (20).

Aside from differences in microcirculation, previously documented sex-significant differences in the pharmacokinetics and pharmacodynamics of propofol may be partially responsible for the sex-related difference in cerebral oxygenation observed during ischemia. Loryan et al. examined the effects of sex on propofol biotransformation in vivo and in vitro (24), and their results suggested sexual dimorphism in the metabolic pathways for propofol elimination and biotransformation. 
Our small sample size and study design prevented us from speculating on the mechanisms behind the difference we observed between the two sexes during cross-clamping and the decrease in oxygenation during extubation between patients receiving propofol anesthesia and those receiving sevoflurane. Therefore, further studies with larger cohorts are warranted to verify our findings.

Emergence agitation is occasionally seen during sevoflurane anesthesia in adults and children (33). Emergence agitation may explain the lower saturation observed before extubation in the sevoflurane group. Changing from sevoflurane to propofol during anesthesia maintenance may reduce the incidence of emergence agitation (36).

Earlier experimental and clinical studies focused on the possible neuroprotective effect of anesthetic preconditioning during cardiac and vascular surgery $(4,13,14,27)$. Sevoflurane has an intrinsic dose-dependent cerebral vasodilatory effect and protects in the brain by reducing $\mathrm{CMRO}_{2}(21,26)$. The carbon dioxide response and cerebral blood flow autoregulation are well maintained during sevoflurane anesthesia (28). The efficacy of propofol in neuroprotection appears to be similar to that of barbiturates (40). Propofol reduces $\mathrm{CMRO}_{2}$ by inhibiting synaptic activity (5). Anesthetic-mediated cerebral protection is efficient only if the anesthetic drug is present at the time of ischemia and more noticeable in focal ischemia than in global ischemia (40). Besides anesthesia, blood pressure, maintenance of normocarbia, and good control of hemodynamic conditions are essential to achieve a favorable outcome in CEA.

Several limitations of this study must be considered. The present study was retrospective by design and included a relatively small number of patients. Nevertheless, evidence from our study can help extrapolate the data obtained in RCTs to real-life settings.

\section{CONCLUSION}

In this study, we hypothesized that a significant difference in $\mathrm{rScO}_{2}$ would be observed between the two groups if sevoflurane or propofol promotes cerebral blood flow or reduced oxygen consumption in the ipsilateral brain during and after cross-clamping. Our results indicate that the NIRS monitor does not show significant differences in cerebral oxygenation during and after cross-clamping in patients undergoing CEA with sevoflurane or propofol anesthesia. The sex-related difference in cerebral oxygenation observed between patients receiving sevoflurane and propofol during the carotid cross-clamping period, as well as the decreased cerebral oxygenation of patients receiving sevoflurane in the ICU during extubation, warrants further study.

\section{REFERENCES}

1. Baumfeld Andre E, Reynolds R, Caubel P, Azoulay L, Dreyer NA: Trial designs using real-world data: The changing landscape of the regulatory approval process. Pharmacoepidemiol Drug Saf 29:1201-1212, 2020
2. Benjamin EJ, Muntner P, Alonso A, Bittencourt MS, Callaway CW, Carson AP, Chamberlain AM, Chang AR, Cheng S, Das SR, Delling FN, Djousse L, Elkind MSV, Ferguson JF, Fornage M, Jordan LC, Khan SS, Kissela BM, Knutson KL, Kwan TW, Lackland DT, Lewis TT, Lichtman JH, Longenecker CT, Loop MS, Lutsey PL, Martin SS, Matsushita K, Moran AE, Mussolino ME, O'Flaherty M, Pandey A, Perak AM, Rosamond WD, Roth GA, Sampson UKA, Satou GM, Schroeder EB, Shah SH, Spartano NL, Stokes A, Tirschwell DL, Tsao CW, Turakhia MP, VanWagner LB, Wilkins JT, Wong SS, Virani SS: Heart disease and stroke statistics-2019 update: A report from the American Heart Association. Circulation 139:e56-e528, 2019

3. Brott TG, Hobson RW, 2nd, Howard G, Roubin GS, Clark WM, Brooks W, Mackey A, Hill MD, Leimgruber PP, Sheffet AJ, Howard VJ, Moore WS, Voeks JH, Hopkins LN, Cutlip DE, Cohen DJ, Popma JJ, Ferguson RD, Cohen SN, Blackshear JL, Silver FL, Mohr JP, Lal BK, Meschia JF, Investigators C: Stenting versus endarterectomy for treatment of carotidartery stenosis. N Engl J Med 363:11-23, 2010

4. Dabrowski W, Rzecki Z, Czajkowski M, Pilat J, Wacinski P, Kotlinska E, Sztanke M, Sztanke K, Stazka K, Pasternak K: Volatile anesthetics reduce biochemical markers of brain injury and brain magnesium disorders in patients undergoing coronary artery bypass graft surgery. J Cardiothorac Vasc Anesth 26:395-402, 2012

5. Fukuda S, Warner DS: Cerebral protection. Br J Anaesth 99:10-17, 2007

6. Gale SD, Hopkins RO: Effects of hypoxia on the brain: Neuroimaging and neuropsychological findings following carbon monoxide poisoning and obstructive sleep apnea. J Int Neuropsychol Soc 10:60-71, 2004

7. Giustiniano E, Alfano A, Battistini GM, Gavazzeni V, Spoto MR, Cancellieri F: Cerebral oximetry during carotid clamping: Is blood pressure raising necessary? J Cardiovasc Med (Hagerstown) 11:522-528, 2010

8. Go AS, Mozaffarian D, Roger VL, Benjamin EJ, Berry JD, Blaha MJ, Dai S, Ford ES, Fox CS, Franco S, Fullerton HJ, Gillespie C, Hailpern SM, Heit JA, Howard VJ, Huffman MD, Judd SE, Kissela BM, Kittner SJ, Lackland DT, Lichtman JH, Lisabeth LD, Mackey RH, Magid DJ, Marcus GM, Marelli A, Matchar DB, McGuire DK, Mohler ER, 3rd, Moy CS, Mussolino ME, Neumar RW, Nichol G, Pandey DK, Paynter NP, Reeves MJ, Sorlie PD, Stein J, Towfighi A, Turan TN, Virani SS, Wong ND, Woo D, Turner MB: Heart disease and stroke statistics--2014 update: A report from the American Heart Association. Circulation 129:e28-e292, 2014

9. Guclu CY, Unver S, Aydinli B, Kazanci D, Dilber E, Ozgok A: The effect of sevoflurane vs. TIVA on cerebral oxygen saturation during cardiopulmonary bypass-randomized trial. Adv Clin Exp Med 23:919-924, 2014

10. Guo JY, Fang JY, Xu SR, Wei M, Huang WQ: Effects of propofol versus sevoflurane on cerebral oxygenation and cognitive outcome in patients with impaired cerebral oxygenation. Ther Clin Risk Manag 12:81-85, 2016

11. Harky A, Chan JSK, Kot TKM, Sanli D, Rahimli R, Belamaric Z, Ng M, Kwan IYY, Bithas C, Makar R, Chandrasekar R, Dimitri S: General anesthesia versus local anesthesia in carotid endarterectomy: A systematic review and meta-analysis. J Cardiothorac Vasc Anesth 34:219-234, 2020 
Cura Z. et al: Cerebral Oxygenation During Carotid Endarterectomy

12. Jeong $\mathrm{H}$, Jeong S, Lim HJ, Lee J, Yoo KY: Cerebral oxygen saturation measured by near-infrared spectroscopy and jugular venous bulb oxygen saturation during arthroscopic shoulder surgery in beach chair position under sevoflurane-nitrous oxide or propofol-remifentanil anesthesia. Anesthesiology 116:1047-1056, 2012

13. Jovic M, Unic-Stojanovic D, Isenovic E, Manfredi R, Cekic O, llijevski N, Babic S, Radak D: Anesthetics and cerebral protection in patients undergoing carotid endarterectomy. $J$ Cardiothorac Vasc Anesth 29:178-184, 2015

14. Kanbak M, Saricaoglu F, Avci A, Ocal T, Koray Z, Aypar U: Propofol offers no advantage over isoflurane anesthesia for cerebral protection during cardiopulmonary bypass: A preliminary study of S-100beta protein levels. Can J Anaesth 51:712-717, 2004

15. Kao WL, Sun CW: Gender-related effect in oxygenation dynamics by using far-infrared intervention with near-infrared spectroscopy measurement: A gender differences controlled trial. PLoS One 10:e0135166, 2015

16. Karasu A, Kuscu DY, Bakac G, Ofluoglu E, Akkoyun N, Yalciner B, Dayan C, Bahar S, Kiris T, Uye M, Toplamoglu H: Carotid endarterectomy with regional anesthesia: An audit of 71 cases. Turk Neurosurg 19:21-28, 2009

17. Katkade VB, Sanders KN, Zou KH: Real world data: An opportunity to supplement existing evidence for the use of long-established medicines in health care decision making. $J$ Multidiscip Healthc 11:295-304, 2018

18. Kato S, Yoshitani K, Ohnishi Y: Cerebral blood flow measurement by near-infrared spectroscopy during carotid endarterectomy. J Neurosurg Anesthesiol 28:291-295, 2016

19. Kernan WN, Ovbiagele B, Black HR, Bravata DM, Chimowitz MI, Ezekowitz MD, Fang MC, Fisher M, Furie KL, Heck DV, Johnston SC, Kasner SE, Kittner SJ, Mitchell PH, Rich MW, Richardson D, Schwamm LH, Wilson JA: American Heart Association Stroke Council CoC, Stroke Nursing CoCC, Council on Peripheral Vascular D: Guidelines for the prevention of stroke in patients with stroke and transient ischemic attack: A guideline for healthcare professionals from the American Heart Association/American Stroke Association. Stroke 45:2160-2236, 2014

20. Kim SJ, Kwon JY, Cho AR, Kim HK, Kim TK: The effects of sevoflurane and propofol anesthesia on cerebral oxygenation in gynecological laparoscopic surgery. Korean $\mathrm{J}$ Anesthesiol 61:225-232, 2011

21. Kondo Y, Hirose N, Maeda T, Suzuki T, Yoshino A, Katayama $Y$ : Changes in cerebral blood flow and oxygenation during induction of general anesthesia with sevoflurane versus propofol. Adv Exp Med Biol 876:479-484, 2016

22. Li J, Shalabi A, Ji F, Meng L: Monitoring cerebral ischemia during carotid endarterectomy and stenting. J Biomed Res 31, 2017

23. Lomivorotov VV, Shmyrev VA, Moroz GB: Volatile anesthesia for carotid endarterectomy: Friend or foe for the brain? J Cardiothorac Vasc Anesth 32:1709-1710, 2018

24. Loryan I, Lindqvist M, Johansson I, Hiratsuka M, van der Heiden I, van Schaik RH, Jakobsson J, Ingelman-Sundberg M: Influence of sex on propofol metabolism, a pilot study: Implications for propofol anesthesia. Eur J Clin Pharmacol 68:397-406, 2012

25. Madsen PL, Secher NH: Near-infrared oximetry of the brain. Prog Neurobiol 58:541-560, 1999
26. Matta BF, Heath KJ, Tipping K, Summors AC: Direct cerebral vasodilatory effects of sevoflurane and isoflurane. Anesthesiology 91:677-680, 1999

27. McCulloch TJ, Thompson CL, Turner MJ: A randomized crossover comparison of the effects of propofol and sevoflurane on cerebral hemodynamics during carotid endarterectomy. Anesthesiology 106:56-64, 2007

28. Mielck F, Stephan H, Weyland A, Sonntag H: Effects of one minimum alveolar anesthetic concentration sevoflurane on cerebral metabolism, blood flow, and $\mathrm{CO} 2$ reactivity in cardiac patients. Anesth Analg 89:364-369, 1999

29. Neimark MI, Shmelev VV, Vlu S: Comparative assessment of inhalation anesthesia with sevofluran and intravenous anesthesia with propofol for carotid endarterectomy. Vestn Khir Im I I Grek 168:66-71, 2009

30. Park S, Yook K, Yoo KY, Choi Jl, Bae HB, You Y, Jin B, Jeong S: Comparison of the effect of sevoflurane or propofol anesthesia on the regional cerebral oxygen saturation in patients undergoing carotid endarterectomy: A prospective, randomized controlled study. BMC Anesthesiol 19:157, 2019

31. Pedrini L, Magnoni F, Sensi L, Pisano E, Ballestrazzi MS, Cirelli MR, Pilato A: Is near-infrared spectroscopy a reliable method to evaluate clamping ischemia during carotid surgery? Stroke Res Treat 2012:156975, 2012

32. Pugliese F, Ruberto F, Tosi A, Martelli S, Bruno K, Summonti D, D'Alio A, Diana B, Anile M, Panico A, Speziale F, Pietropaoli $P$ : Regional cerebral saturation versus transcranial Doppler during carotid endarterectomy under regional anaesthesia. Eur J Anaesthesiol 26:643-647, 2009

33. Ramroop R, Hariharan S, Chen D: Emergence delirium following sevoflurane anesthesia in adults: Prospective observational study. Rev Bras Anestesiol 69:233-241, 2019

34. Rigamonti A, Scandroglio M, Minicucci F, Magrin S, Carozzo A, Casati A: A clinical evaluation of near-infrared cerebral oximetry in the awake patient to monitor cerebral perfusion during carotid endarterectomy. J Clin Anesth 17:426-430, 2005

35. Shang Y, Cheng R, Dong L, Ryan SJ, Saha SP, Yu G: Cerebral monitoring during carotid endarterectomy using near-infrared diffuse optical spectroscopies and electroencephalogram. Phys Med Biol 56:3015-3032, 2011

36. Uezono S, Goto T, Terui K, Ichinose F, Ishguro Y, Nakata Y, Morita S: Emergence agitation after sevoflurane versus propofol in pediatric patients. Anesth Analg 91:563-566, 2000

37. Yu B, Peng Y, Qiao H, Liu B, Wang M, Yang X, Han R: The application of regional cerebral oxygenation monitoring in the prediction of cerebral hypoperfusion during carotid endarterectomy. J Neurosurg Anesthesiol, 2020 (Online ahead of print)

38. Zhang HP, Ma XD, Chen LF, Yang Y, Xu BN, Zhou DB: Cognitive function after carotid endarterectomy: Early decline and later recovery. Turk Neurosurg 26:833-839, 2016

39. Zhang Y, Zhang FG, Meng C, Tian SY, Wang YX, Zhao W, Chen J, Zhang XS, Liang Y, Zhang SD, Xing YJ: Inhibition of sevoflurane postconditioning against cerebral ischemia reperfusion-induced oxidative injury in rats. Molecules 17:341-354, 2011

40. Zwerus R, Absalom A: Update on anesthetic neuroprotection. Curr Opin Anaesthesiol 28:424-430, 2015 